\title{
In Use Monitoring of Public Buildings. Case Study in North Italy
}

\author{
Chiara Delmastro *, Guglielmina Mutani and Stefano Perassi \\ Politecnico di Torino, Department of Energy, C.so Duca degli Abruzzi 24, 10129, Torino \\ Email: chiara.delmastro@polito.it
}

\begin{abstract}
Urban areas have become energy intensive hubs that need of solutions for significantly reduce carbon emission in the next decades. For that reason, the exploration of different energy conservation measures alternatives is crucial for meeting the desired environmental goals.

In such contest, the paper proposes a procedure, based on real-time monitored data, for characterizing the thermal and electric consumption of urban public buildings (schools, offices, etc.). The paper aims at providing rich information about the building performances and occupation schedules for finding opportunities for better control/regulation/energy service contracts strategies for operating public buildings. The procedure is applied to case study buildings in Rivalta di Torino and demonstrates that most of buildings can really benefit from this analysis leading to a more comfortable work environment and contemporary reducing their energy consumption at an affordable cost.
\end{abstract}

Keywords: Public buildings, Monitoring, Diagnostic, Energy conservation measure.

\section{INTRODUCTION}

In last decades, many efforts have been done for reducing the energy consumption of public and residential buildings. Main pillars are the application of European directives [1] for enhancing the performance of new buildings and the renovation of existing ones and energy conservation measures [2,3,4]. Main drivers for energy consumption in buildings are climate, building physical characteristics, destination use, users characteristics, occupant behavior, socio-economic factors, and indoor air quality requirements [5]. Some of these factors are related to design and construction phase, but others are related to the final use of the building. This multitude of factors leads to construct buildings that consume much more then predicted. Overcoming the discrepancy between estimated and real energy consumption of buildings still represent a great challenge. In particular, with the increase of Buildings Standard requirements, operational aspects become key drivers of global energy performances.

Understanding how energy is consumed and related to users occupation profiles can help to identify energy conservation measures and management options. Energy monitoring allows increasing the knowledge of the system (energy loads, operation conditions, maintenance requirements etc.) and for that reason many researchers have recently adopted this technique. In particular, [6] assessed that, from monitoring data, Energy Performance Indicators should be evaluated in order to compare different buildings. Eight schools in Portugal have been analyzed by [7] for investigating main reasons for consumption increasing after renovation measures. Menezes et al. [8], estimates the discrepancy between estimated and real electricity consumption in an office building and demonstrated that by knowing this information, more precise consumption models can be built. Monitoring data analysis exploiting regression techniques have been proposed by [9] for reducing the electric consumption in Korean schools. In Greece, [10] monitored temperatures and indoor air quality parameters in 320 schools for comparing energy consumptions by using clustering techniques. In Italy, [11] installed heat meters in 120 schools for evaluating the gap between estimated and real thermal consumptions. Similarly, [12] monitored heat consumptions in 49 schools for identifying main necessary renovation measures. In the work of [13], a monitoring network has been installed in a university and electric consumption data have been gathered at for the different zones; they demonstrated that the disaggregated level of data allows finding the most energy intensive areas and that contributes to consumption reduction strategies. Yang et al. [14], estimated the impacts of thermal consumptions on the environment by monitoring the thermal comfort of buildings using PMV and PPD methods. Batista et al., [15] identified linear correlations between refrigeration loads and electric consumption through a continuous monitoring system. The necessity of proper data analysis and filtering procedures has been stressed by [16]. De Wilde et al. [17] explored how simulation approaches can be fused into energy management practice where historical profiles are not available. Toward control automation, [18] proposed a wireless sensors system for assessing the potential energy consumption reduction. Four monitoring approaches have been presented and 
compared by [19]: manual systems, self- built system, local distribution companies systems and external service provider systems. Results suggested that being supported by external service provider systems might lead to more accurate and precise data.

The purpose of this paper is to contribute to current research by presenting a procedure, which can be easily accessible, self-made and replicable to other case studies. Final goal is building-up data-driven energy models (correlations between energy consumptions and monitored variables) in order to exploit the real data collected by sensors. The analysis is helpful for detecting main deviancies from normal operation conditions and to diagnostic the opportunities of introducing new conservation measures. The procedure has been applied to 6 public buildings in Rivalta di Torino, North-West of Italy and the monitoring process started in 2013.

The structure of the paper is as follow. Section 2 describes the methodological framework; Section 3 defines the case study; Section 4 presents and discusses the main results and Section 5 presents the energy conservation opportunities. Conclusions are summarized in Section 6.

\section{METHODOLOGY}

This section aims at presenting the measurement framework adopted in the work. The framework has been applied and tested in public buildings. Steps of the research include: i. identification of relevant buildings and definition of the energy consumption metrics; ii. identification of the sensors to be used; iii. modeling techniques for analyzing the measured data; iv. identification of possible conservation measures.

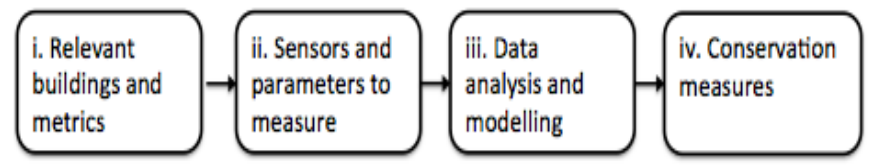

Figure 1. Steps of the analysis

\subsection{Definition of relevant buildings and energy consumption metrics}

Public buildings have four main energy expenses: i. electricity consumption; ii. thermal consumptions; iii. fuel cost for transportation services and iv. operation and maintenance of the energy systems. This study is focused both on energy (thermal and electric) consumptions and operation schedules of buildings. Electric consumption includes services for buildings only, neglecting the share used for public lighting of streets and outdoor spaces.

Buildings to be monitored have been chosen in accordance with their consumption levels (taking into account the most relevant energy service e.g. space heating).

For the buildings, six main energy related parameters have been monitored: electricity consumption, gas consumption, indoor temperature, outdoor temperature, and solar irradiation. Moreover, components with high thermal dispersions are detected with thermal imager.

\subsection{Identification of parameters and sensors}

The choice of sensors in this works has been effected by two main contextual factors: $i$. the variables to be measured and ii. the fiscal availability of costumers. All the sensors inside the buildings have been sited according to the orientation and the surface to volume ratio of the rooms in order to avoid the acquisition of incorrect data.

\subsubsection{External air temperature and relative humidity}

External air temperature is necessary for the estimation of heating degree-days (HDD). A private weather station (Vantage Pro 2 with accuracy $\pm 0,5^{\circ} \mathrm{C}$ ), sited closest to the monitoring sites (Prabernasca), has been used as reference (Fig. 2a).

\subsubsection{Solar irradiation}

The weather station described in section 2.2.1 is not provided of a solarimeter, thus data have been collected from the ARPA (the Regional Association for Environment Protection) weather station of Caselle Torinese. Solar irradiation values are useful to understand the trend of lighting consumption.

\subsubsection{Indoor air temperature and relative humidity}

For measuring internal air temperature and relative humidity the data-logger Lascar EL-USB-2+ (temperature sensor NTC $10 \mathrm{~K}$ with a resolution of $\pm 0.5^{\circ} \mathrm{C}$ and a declared accuracy of $\pm 0.5{ }^{\circ} \mathrm{C}$ at $20^{\circ} \mathrm{C}$ and relative humidity sensor with $0.1 \%$ resolution, $\pm 2.5 \% \mathrm{HR}$ accuracy at $150 \mathrm{pF}, 23^{\circ} \mathrm{C}$ and $30 \% \mathrm{HR}$ ) has been chosen (Fig 2.b). 16,382 relative humidity sample values can be collected and stored in the data-logger with gathering intervals that can vary from 10 s to $12 \mathrm{~h}$. For this analysis, hourly data have been collected. Every analyzed building has been divided in thermally homogeneous zones. Indoor air temperature values provide information about the regulation of the energy system.

\subsubsection{Electricity consumption}

For monitoring electric consumption, the pulse metering technique has been adopted. Public buildings are equipped with electric meters (Fig. 2f) provided with two leds that pulse every time a Wh is consumed. By counting these pulses it is possible to evaluate the electricity consumption. The data-logger EL-USB-5 (software EasyLog USB) coupled with a photoresistance has been used to acquire the pulse signal (Fig. 2c). The data logger has been set for a voltage range of $0-3 \mathrm{~V}$ (low trigger voltage of $0.8 \mathrm{~V}$ and high trigger voltage of $2.0 \mathrm{~V}$ ) and counts events in a period of $5 \mathrm{~min}$. Electricity consumptions provide information about the occupation schedule of the buildings.

\subsubsection{Natural gas consumption}

The monitoring of natural gas is provided by gas meters G40 $\left(\max 40 \mathrm{~m}^{3} / \mathrm{h}\right)$ or higher. Standardizers (Corus) to convert cubic meters $\left(\mathrm{m}^{3}\right)$ in Standard cubic meters $\left(\mathrm{Sm}^{3}\right)$ have been installed (Fig. 2d and Fig. 2f). Natural gas consumption provides information about the operation schedule of the heating system.

\subsubsection{Thermal dispersions}

Two thermal cameras have been used in this work: the NEC TH 7100 (Fig. 2g) and the Radiamatic Timage.

Emissivity values have been set between 0.8 and 0.9 for taking into account the different materials of the envelope characterizing the buildings. Thermal camera results provide 
precious information about thermal dispersions of the structures.

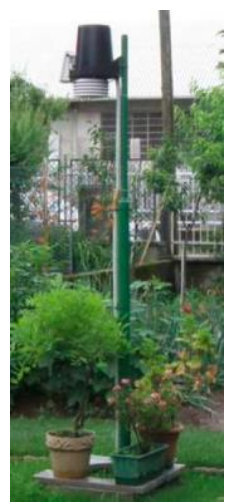

(a)weather station

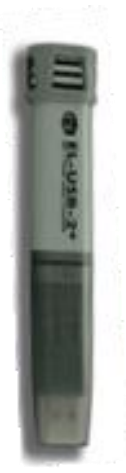
logger
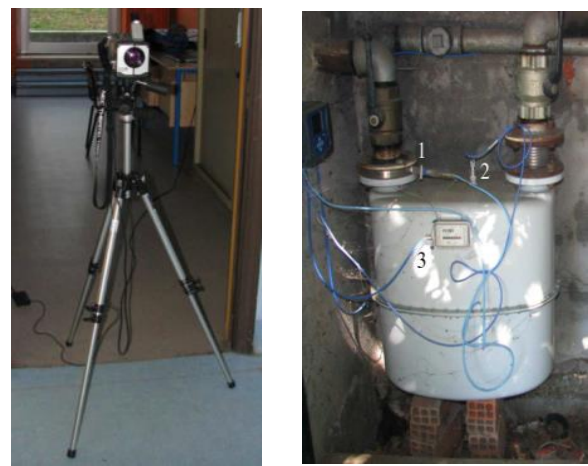

(g)thermal camera (b) indoor $\mathrm{T}$ data

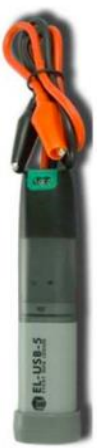

(c) pulse signal

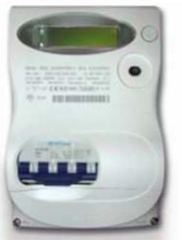

(e)electric counter

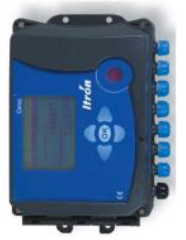

(f) gas counter
Figure 2. Sensors

\subsection{Data analysis and modeling}

To analyze collected data, both qualitative and quantitative evaluations are proposed.

\subsubsection{Qualitative analyses}

Qualitative analyses graphically provide useful information about the trend of the measured variables. In this work, the following qualitative analyses are proposed:

(1) "carpet plot" (matrices with daily hours as rows and days as columns): the trend during the analyzed time period of indoor and outdoor temperature as well as electric consumption can be tracked by these maps. A color scale is associated to consumption values (red $=$ high values; blue = low values). These kinds of information are useful for visualizing regulation information and identifying anomalies during the operation (e.g. from external temperature in Fig.3 can be identified the presence of the fohn wind at the end of January from 3 to 7 a.m.).

(2) "indoor temperature vs. shape factor and orientation": from this analysis, the effects of orientation and zone compactness can be correlated with indoor temperatures values; this information is also useful to install correctly the probes.

(3) thermography analysis for identifying thermal dispersions in the structures.

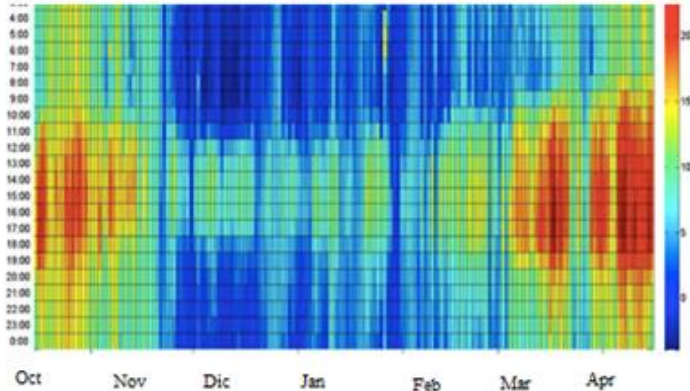

Figure 3. Carpet plot of the external temperature (2013-2014 heating season)

\subsubsection{Quantitative analyses}

The quantitative analyses aims at modeling the behavior of the measured parameters. Quantitative analyses are based on:

(1) the creation of graphs that relate the trend of energy consumption (thermal, electric and gas) with respect to their drivers (e.g. Heating Degree Days HDD) with a hourly, weekly or monthly resolution;

(2) the creation of load diagrams for typical days of a month (considering not working and working days).

In particular, a multiple linear regression model Eq. (1) has been proposed to reproduce the performance of daily electrical energy-use (Elc, kWh) as function of three main components [20]:

(1) k1: fixed value representing the electric usage that is not function of climate $(\mathrm{kWh})$

(2) $\mathrm{k} 2$ : value that depends on the gradient of solar irradiation (e.g. influencing lighting consumptions) (kWh)

(3) $\mathrm{k} 3$ : value that depends on the gradient of air temperature (e.g. influencing energy consumptions of electric appliances) $(\mathrm{kWh})$

$E l c=k 1+k 2 * \frac{20-T m}{D T_{\text {average }}}+k 3 * \frac{I \max -I m}{D I_{\text {average }}}$

where:

Elc $=$ the average daily consumption evaluated on a monthly base $(\mathrm{kWh})$;

$\mathrm{Tm}=$ the average monthly temperature of external air temperature $\left({ }^{\circ} \mathrm{C}\right)$;

$\mathrm{DT}_{\text {average }}=$ the annual average gradient of air temperatures $\left({ }^{\circ} \mathrm{C}\right)$;

Imax $=$ the maximum daily irradiation over the year $\left(\mathrm{kWh} / \mathrm{m}^{2}\right)$;

$\mathrm{Im}=$ the monthly average value of daily solar irradiation $\left(\mathrm{kWh} / \mathrm{m}^{2}\right)$.

$\mathrm{DI}_{\text {average }}=$ the annual average gradient of solar irradiation $\left(\mathrm{kWh} / \mathrm{m}^{2}\right)$.

For the monthly electrical consumption, the number of working days of each month has been evaluated considering the scholastic calendar.

\subsection{Energy conservation measures proposals}

From the analysis of monitored data, main deviancies from normal operation conditions can be identified and opportunities of introducing new conservation measures can be highlighted.

In this study, proposals of conservation measures focus on: 
(1) Opportunities for new thermal regulation schedules: optimizing the operation hours of the energy system and reducing the internal temperature during not occupied periods.

(2) Opportunities for envelope components and energy devices substitutions.

All the previous measures are leading to economic benefits related to energy savings intervention, nevertheless could be interesting to explore as well measures that may provide economic profits without affecting the energy-use. In this paper opportunities for new electric supply contracts are analyzed when the installed electric power is oversized with respect to the buildings' needs: a new contract with advantageous tariffs can be proposed in this case.

\section{THE CASE STUDY}

The analysis has been performed on public buildings sited in Rivalta di Torino, North-West of Italy. The municipality has 20,000 inhabitants and owns 16 public buildings. All the buildings are heated with natural gas. From the analysis of the energy bills of 5 consecutive years (2009 - 2014), resulted that thermal consumption, due to space heating and hot water production, accounts for $58 \%$ of total primary energy consumption $(5,94 \mathrm{GWh} / \mathrm{yr})$ while electricity $(4,39$ $\mathrm{GWh} / \mathrm{yr}$ ) are responsible of $42 \%$ (of which the $30 \%$ for buildings and $70 \%$ for public lighting). The destination use of buildings is: educational (11), office (1), library (1) and cultural site (3).

Since thermal consumption represents the most energy intensive end-use service, it has been chosen for identify the buildings to be monitored. Six buildings with high thermal energy consumption have been thus observed from October 2013 to January 2015 (Table 1).

The municipality (Building 1) has been built before the ' 80 s. From 2009 to 2014 , it yearly averagely consumed about $32,000 \mathrm{~m}^{3}$ of gas and $111 \mathrm{MWh}$ of electricity. It is heated by a condensing boiler and refrigerated by a chiller. For this building, electric consumption for lighting, appliances, water heating and space cooling have been monitored.

The Don Milani secondary school (Building 2) has been built in 1097 and it is an ex monastery. From 2009 to 2014, it yearly averagely consumed about $84,970 \mathrm{~m}^{3}$ of gas and 75 MWh of electricity. Two condensing boilers provide heat to the building. The structure is a school but also host congress and summer evening events, affecting electric consumption profiles. Six homogeneous zones in terms of temperature have been identified, thus six temperature sensors have been installed.

The Sangone primary school (Building 3 ) has been built in the '70s and host a gym and an auditorium too. From 2009 to 2014 , it yearly averagely consumed about $71,240 \mathrm{~m}^{3}$ of gas and $81 \mathrm{MWh}$ of electricity. The school is heated by two boilers, one for space heating $(830 \mathrm{~kW})$ and another one for hot water production $(279 \mathrm{~kW})$. Six sensors have been installed for measuring indoor temperatures.

The Gerbole primary school (Building 4) has been constructed in the ' 80 s. From 2009 to 2014, it yearly averagely consumed about $49,060 \mathrm{~m}^{3}$ of gas and $23 \mathrm{MWh}$ of electricity. This building has been subjected to renovation measures during the monitoring period (windows have been substituted in 2012, the energy system has been refurbished in 2014: new boilers, new storage and thermostatic valves installations. Three temperature sensors have been installed in the building.

The Tetti primary school (Building 5) dates back to the '70s. From 2009 to 2014 , it yearly averagely consumed about $61,700 \mathrm{~m}^{3}$ of gas and $36 \mathrm{MWh}$ of electricity. In the ' $90 \mathrm{~s}$, the heat boilers have been substituted with new ones for a total of about $815 \mathrm{~kW}$. Four sensors for indoor temperature measurements have been installed.

The Tetti secondary school (Building 6) was built in the ' 80 s. From 2009 to 2014 , it yearly averagely consumed about $52,400 \mathrm{~m}^{3}$ of gas and $45 \mathrm{MWh}$ of electricity. In 2010, a PV system has been installed on the roof. Electric consumption only has been monitored for this building.

Table 1. Monitored buildings and variables

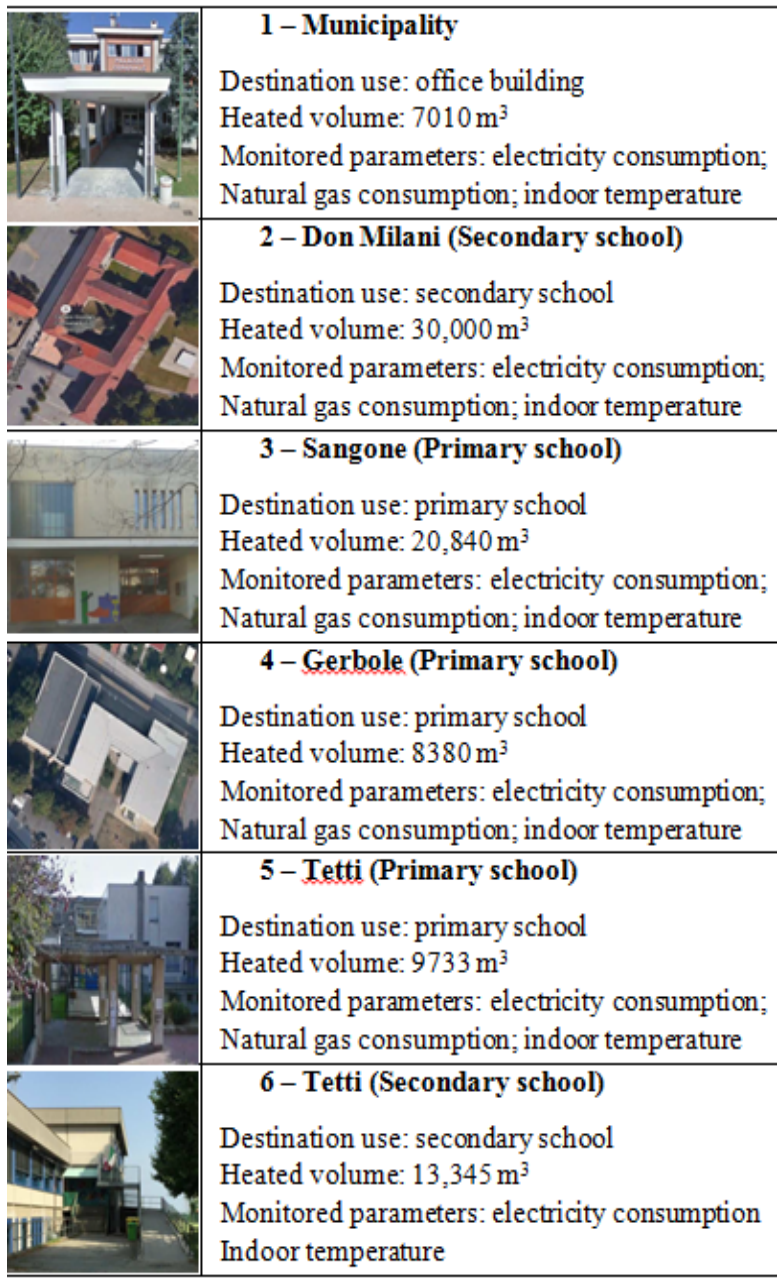

\section{RESULTS}

In this section, results of qualitative and quantitative analyses are presented.

\subsection{Electric consumption}

In this section main results concerning electric consumption are highlighted.

\subsubsection{Building 1 - Municipality}

From the carpet plot (Fig.4a) can be realized that the electric base load by night and during the week-end is equal to $8 \mathrm{~kW}$. From 8 am to $8 \mathrm{pm}$ (working hours), consumptions 
are more than double with respect to the base load. Moreover, during summer, the energy consumption assumes higher values with respect to winter period for space cooling. From the load diagram (Fig.4b) of a typical day of the year (data gathered every 5 minutes), the trend of electric consumption can be observed: during the working days there is a peak from 10 am to 12 am and around $6 \mathrm{pm}$; moreover it confirms that the base load is equal to $8 \mathrm{~kW}$ (nights and week-ends). By analyzing data throughout the monitoring period can be detected that the maximum required power is $40 \mathrm{~kW}$, but the available electric power of the building is 70 $\mathrm{kW}$

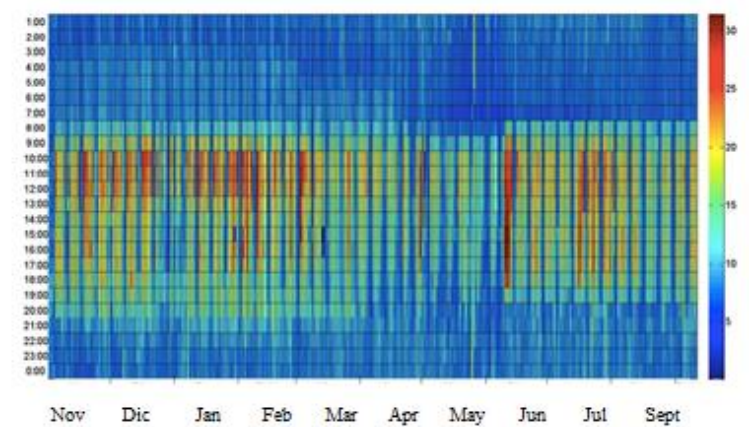

(a) carpet plot of electric consumption

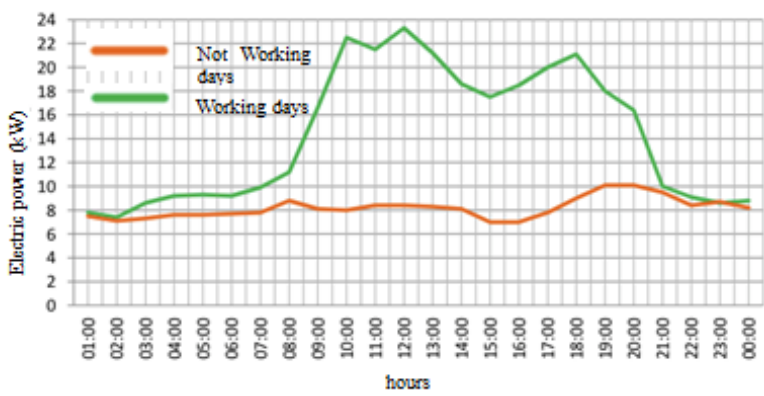

(b) electric load diagram for a typical day

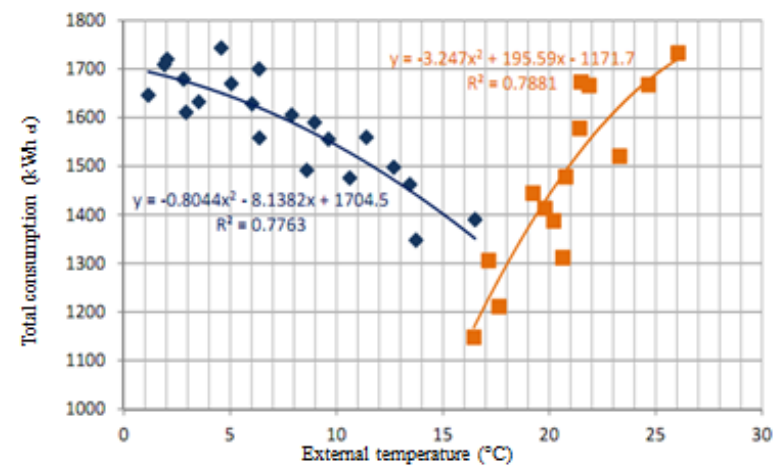

(c) electric weekly consumptions vs external temperature

Figure 4. Electricity power $(\mathrm{kW})$ of Building 1

This consideration is helpful for evaluating possible changes in the electricity service contract. In Fig. 4c, the relationship between weekly electric consumptions (working days only) and external temperature is provided. The blue trend is related to the winter period while the orange one is related to the summer period. The trend of external temperature is driven by solar irradiation and consequently, winter electric consumption are higher with lower temperatures due to the needs of lighting inside the rooms. During the summer period, the trend is opposite since high irradiations values and high temperatures drive the necessity of space cooling.

\subsubsection{Building 2 - Don Milani Secondary School}

From the monitored electric consumption data, the occupation schedule of the building can be understood: the building is used during the morning, the afternoon and the evening from Monday to Friday; while, during the week-end, it is occupied the evenings only. From the carpet plot, vacation period (July-September) and winter periods (base load of $8 \mathrm{~kW}$ instead of $3 \mathrm{~kW}$ ) are clearly visible. Similarly to the municipality (Building 1), the maximum required power is $31 \mathrm{~kW}$, but the available electric power of the building is $90 \mathrm{~kW}$. Consequently, there are possibilities for changing the supply contract into a more advantageous one. Fig. 5 shows that the model Eq. (1) with the coefficient of Tab. 2 correctly approximates the electric consumption.

Table 2. Values of the constant of Eq. (1) for Building 2

\begin{tabular}{c|c|c}
\hline $\mathrm{k} 1$ & $\mathrm{k} 2$ & $\mathrm{k} 3$ \\
\hline 341.1 & 34.8 & 0 \\
\hline
\end{tabular}

From Tab. 2 can be observed that for this specific building, the irradiation is not affecting the electric consumption trends and also the variable contribution related to external temperature is low (9\%) while a high contribution is due to $\mathrm{k} 1$ (fix load). This means that the regulation of lighting is not affected by the natural daylighting as could be expected by a school in a historical monastery.

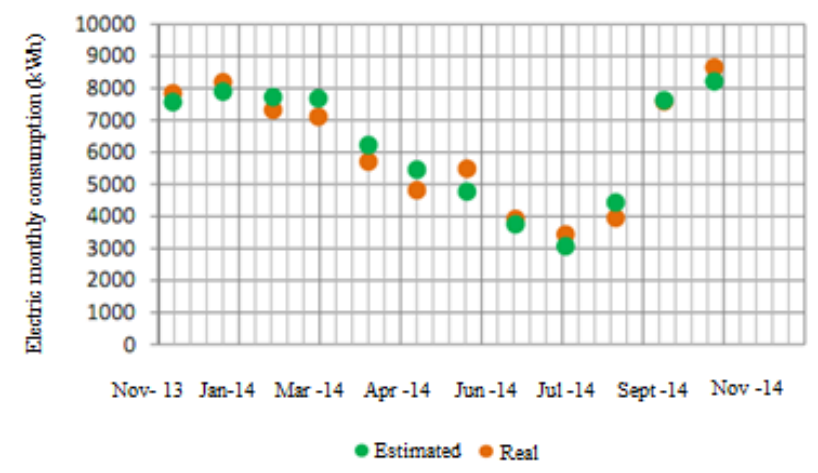

Figure 5. Real and estimated electricity monthly consumption $(\mathrm{kWh})$ of Building 2

\subsubsection{Building 3 - Sangone Primary School}

As well as for Building 2, winter periods (base load of 8 $\mathrm{kW}$ instead of $3 \mathrm{~kW}$ ) are clearly visible in the carpet plot. During week days, electric consumption are increasing around 8 am with a peak around $1 \mathrm{pm}$ for food preparing, dish washing and cleaning. At 6 pm consumption starts decreasing until $11 \mathrm{pm}$ (lighting and sport activities still present).

During winter periods, as well as for Building 1, weekly electric consumption is growing for lower temperature with a quadratic trend (Fig.6). For this building any anomalies in terms of electric consumption have been detected. In Tab.3, the contributions of climate (irradiation and external temperature) to electricity consumptions can be noticed. The contribution of irradiation is higher (19\%) with respect to temperature $(14 \%)$ and compared to Building 2, the contribution of the fix consumption load is lower. 


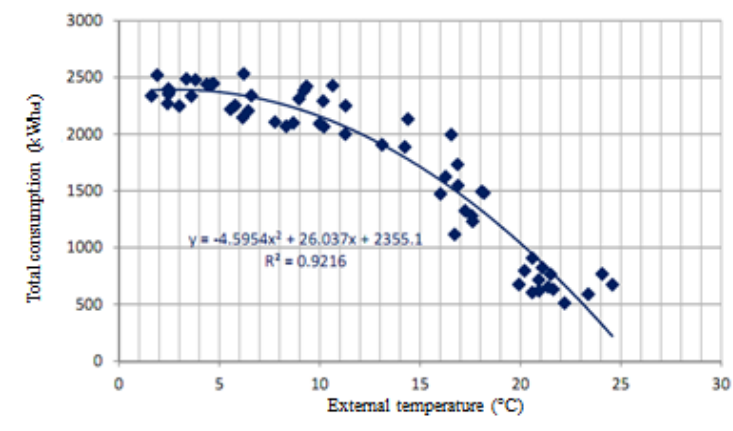

Figure 6. Electric weekly consumption vs. external temperature (Building 3)

Table 3. Values of the constant of Eq. (1) for Building 3

\begin{tabular}{c|c|c}
\hline $\mathrm{k} 1$ & $\mathrm{k} 2$ & $\mathrm{k} 3$ \\
\hline 277.2 & 56.3 & 76.3 \\
\hline
\end{tabular}

\subsubsection{Building 4 - Gerbole Primary School}

From the carpet plot, it is clear that the building is used during the week only. During the evening the electric load is $5 \mathrm{~kW}$ and at night is $1 \mathrm{~kW}$. The maximum required power is $18 \mathrm{~kW}$ but the buildings have an installed power of $33 \mathrm{~kW}$. Even in this case can be interesting to explore the effects of a change in the supply contract. In Fig. 7, can be seen that the linear model (1) fits the electric consumption. Similarly to building 3 , the variable contribution of climate is observed $(\mathrm{k} 1=56.6, \mathrm{k} 2=7.7$ and $\mathrm{k} 3=59.6)$ with a higher contribution of irradiation (48\%).

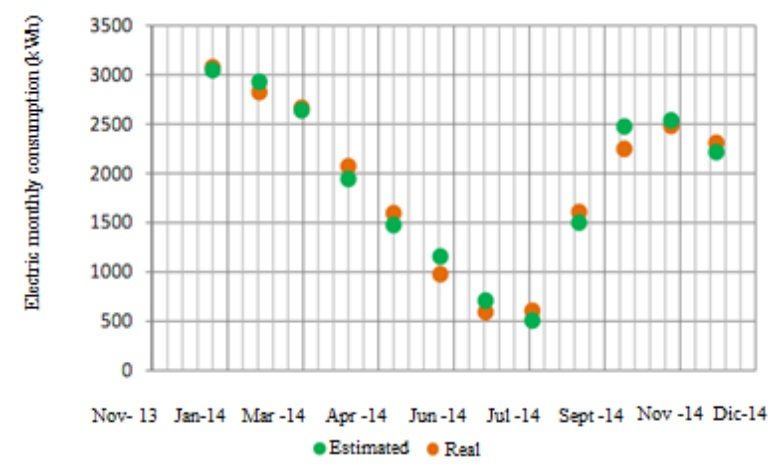

Figure 7. Real and estimated electricity monthly consumption $(\mathrm{kWh})$ of Building 4

\subsubsection{Building 5 - Tetti Primary School}

The carpet plot of this building is similar to the one of Building 4 meaning that school has a weekly occupation (typical day as in Fig. 8) and most of electric consumption is related to lighting. Any anomalies are detected. For this building the required electric power is $26 \mathrm{~kW}$ and the available power $28 \mathrm{~kW}$, thus if any lamps substitution is planned, the supply contract is suitable for the usage of the building. For this building, the correlation between climate variables and electric consumption Eq. (1) is different with respect to the previous buildings in fact both the contributions of irradiation and temperatures gradients are present, but with a higher contribution $(18 \%)$ of temperature gradient $(\mathrm{k} 1=144.2, \mathrm{k} 2=32.9$ and $\mathrm{k} 3=6.8)$. In Fig. 9 the daily electrical consumption is represented considering the working days of the scholastic calendar.

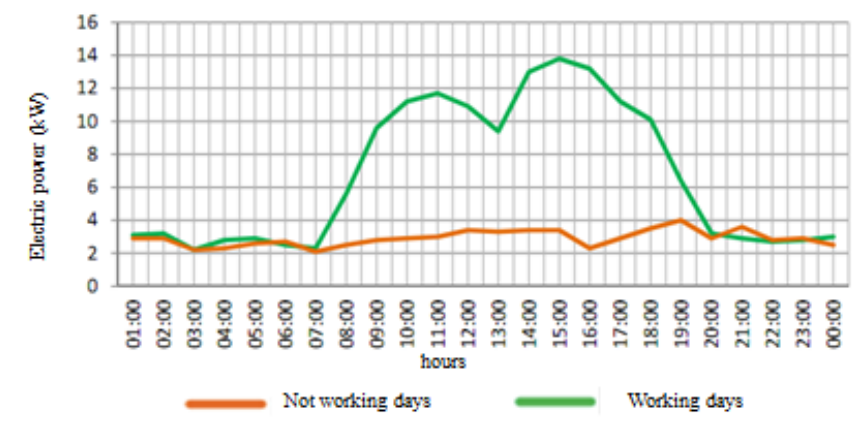

Figure 8. Electric load diagram for a typical day (Building 5)

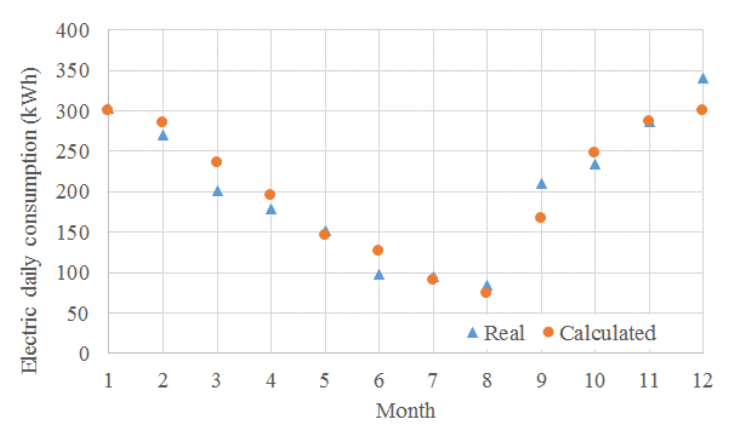

Figure 9. Real and estimated electricity daily consumption of Building 5

\subsubsection{Building 6 - Tetti Secondary School}

This building is provided by a PV system of $10.3 \mathrm{~kW}_{\mathrm{p}}$ (occupied roof surface of about $64 \mathrm{~m}^{2}$ ), consequently from March to September a great part of electric needs during the day are supplied by renewable energy sources. The available installed electric power is $33 \mathrm{~kW}$ and the required power is 23 $\mathrm{kW}$. Considering the presence of the PV system could be interesting to analyze the effect of changing the supply contract by reducing the installed power.

\subsection{Thermal consumption}

This section summarizes main results related to gas consumption and internal temperature monitoring.

\subsubsection{Building 2 - Don Milani Secondary School}

The principal destination use of Building 2 is for education, but the structure is used for cultural and sport activities as well. Observing the internal temperature trend of the school for two consecutive years (2013- 2014 and 20142015), a significance difference in terms of regulation is highlighted (Fig. 10). By investigating the reason of such anomaly, a change in the local company for managing the thermal energy system has been detected. The average internal temperature increased from $20.1^{\circ} \mathrm{C}$ (winter season 2013-2014) to $21.8{ }^{\circ} \mathrm{C}$ (winter season 2014-2015) with a consequent increase of consumption of about $6 \%$. In Fig. 11 the impact of regulation change on thermal energy consumption can be observed.

From the data gathered from the gas counter can be detected that natural gas is consumed:

(1) $44 \%$ of from $5 \mathrm{am} 5 \mathrm{pm}$ and (Monday to Friday) 
(2) $29 \%$ from 5 pm to 4 am (Monday to Friday)

(3) $14 \%$ of natural gas is consumed from 5 am 5 pm (Saturday and Sunday)

(4) $13 \%$ from 5 pm to 4 am (Saturday and Sunday).

The energy system is always turned on and the $27 \%$ of gas is consequently consumed during the weekend when the building is occupied only during the evening (information achieved by electricity consumption data). From this evidence, about $50 \%$ of daily gas consumption can be saved during the weekend by considering that the building is not occupied. The same logic can be applied to the night gas consumption. A total gas consumption reduction of $21 \%$ can be achieved through a nighttime regulation.

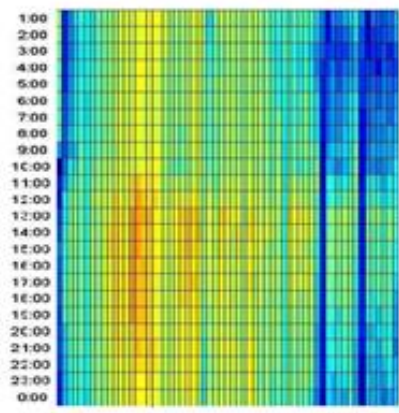

ner 2013

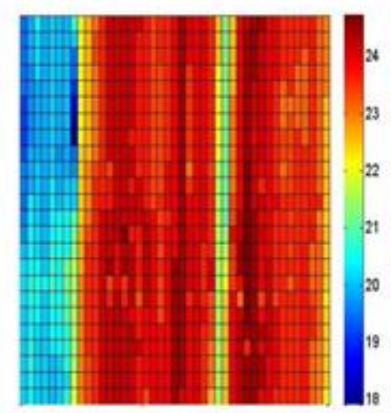

net $2014 \quad$ Nov 2014
Figure 10. Internal temperatures of Building 2

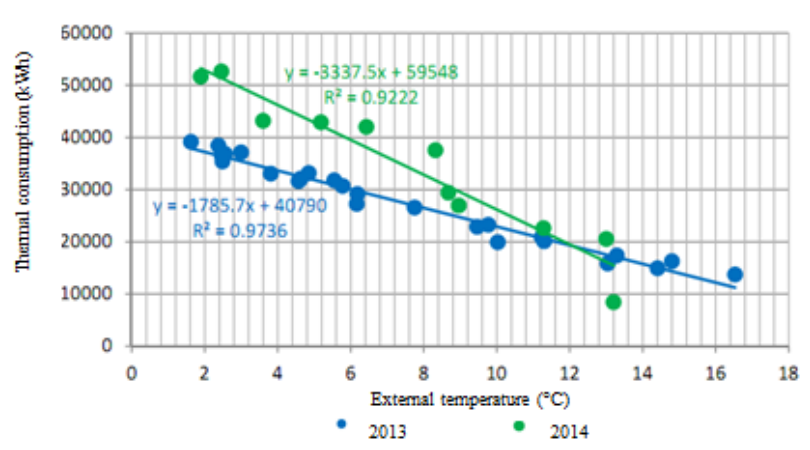

Figure 11. Thermal consumption vs. external temperature (Building 2)

\subsubsection{Building 3 - Sangone Primary School}

During the 2013-2014 winter season, the Primary school maintained an internal temperatures higher than $20^{\circ} \mathrm{C}$ (reference Normative value) with peaks close to $26^{\circ} \mathrm{C}$ (Fig. 12 and Fig.13). The internal temperature has been monitored separately for the different thermal zones; results demonstrate that the thermal regulation is diverse for different zones (Fig.12).

The same values have been monitored for the 2014-2015 heating period, with average internal temperature of $21.5^{\circ} \mathrm{C}$. Moreover, any distinctions from weekly and not weekly days are observed.

Fig.14 shows the linear correlations between HDD and weekly gas consumption considering the current regulation condition. It highlights that to each variation of $1{ }^{\circ} \mathrm{C}$ of internal temperature corresponds a $6.5 \%$ variation of gas consumption. From gas consumption data can be seen that $18 \%$ of gas is consumed during the week-end and $15 \%$ during night of weekly days (Figg. 15a and 15b): by turning off the heating system during these hours, a 33\% gas savings can be achieved without reducing comfort levels during the occupation periods.

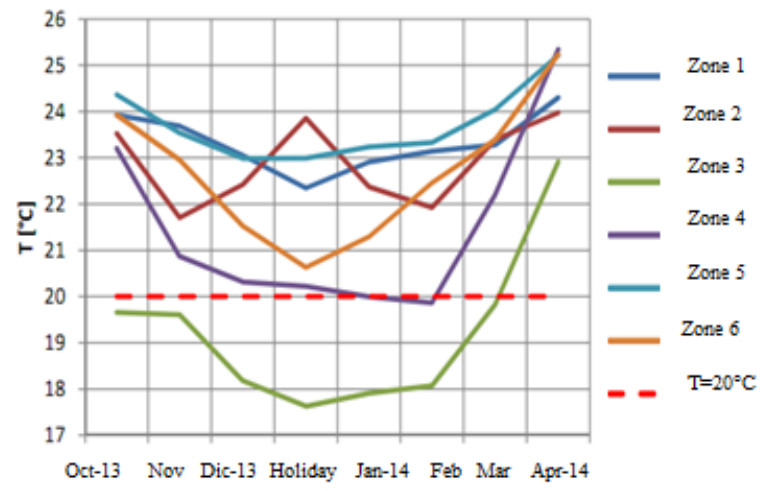

Figure 12. Internal temperature trend for the different zones (Building 3)

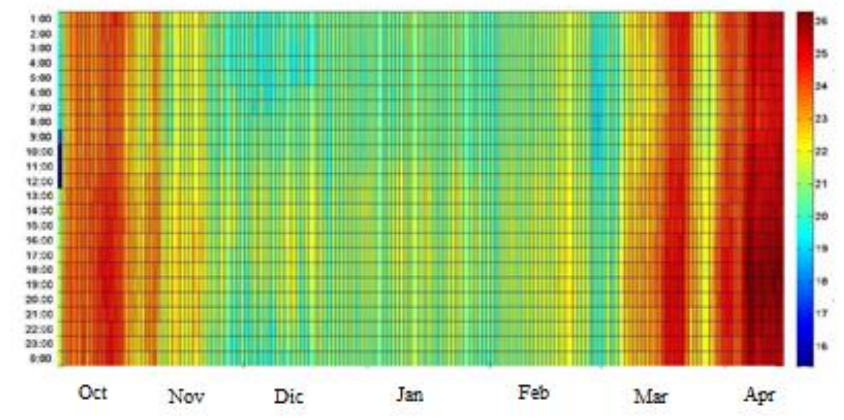

Figure 13. Internal temperature variations $\left({ }^{\circ} \mathrm{C}\right)$ (Building 3$)$

The yearly base gas load is related to the production of hot water; during the summer period, only the guardian of the structure and its family are producing hot water for domestic use. Their daily gas consumption for domestic hot water production is equal to $24 \mathrm{Sm}^{3} / \mathrm{d}$. Considering that a person uses 501 of hot water a day at $50^{\circ} \mathrm{C}$, a family composed by 5 persons will consume $1.7 \mathrm{Sm}^{3} / \mathrm{d}$ of gas for domestic hot water production. Therefore, the consumption of $24 \mathrm{Sm}^{3} / \mathrm{d}$ denotes an inefficient use of the boiler. The $270 \mathrm{~kW}$ gas boiler heats a storage vessel of 20001 for distributing separate hot water respectively to the school (gym and the kitchen) and to the guardians' house. Both of the circuits are maintained in temperature during the whole day leading to unnecessary gas consumption.

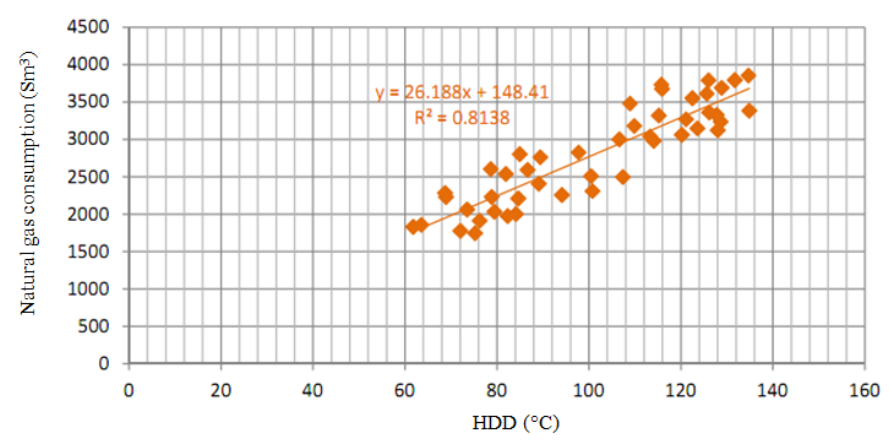

Figure 14. Thermal consumption vs. HDD (Building 3) 


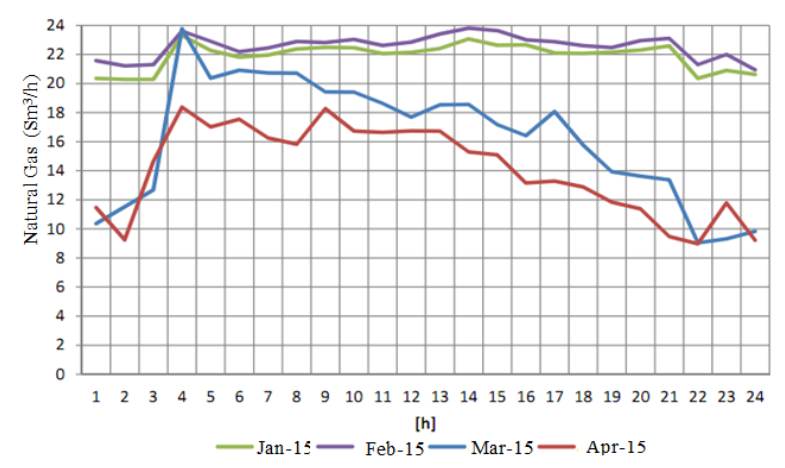

(a) during week days

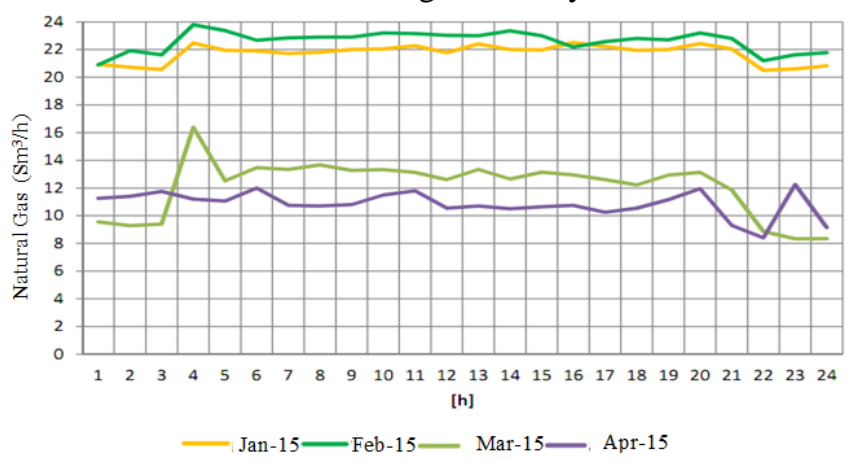

(b) during week - end days

Figure 15. Natural gas consumptions (Building 3)

\subsubsection{Building 4 - Gerbole Primary School}

During the monitoring period, the existing boilers have been substituted with new condensing ones together with the insulation of the distribution system, the substitution of hot water storage and the installation of thermostatic valves. The positive effects (30\% energy savings) of the measures can be seen in Fig. 16.

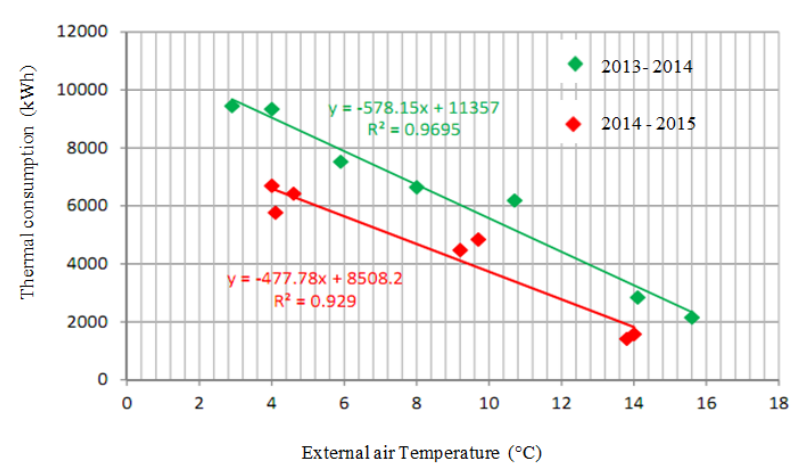

Figure 16. Thermal consumption vs. external temperature (Building 4)

From the data gathered from the gas counter after the renovation measures, can be observed that the heating system is turned on from 6 am to 9 pm during the whole week. The $27 \%$ of gas is consumed during weekend days and $19 \%$ of gas is consumed during the nights of the week (Fig.17a and Fig.17b). By optimizing the regulation in these periods (turning off the system during the nights and reducing the working hours during the week end), $32 \%$ of gas can be saved.

In Fig. 18 the hourly percentage of energy consumption is represented. During the daytime the energy consumption is constant on a percentage of $5 \%$, with peaks of $7 \%$ in the coldest months and 9-11\% in March and April.

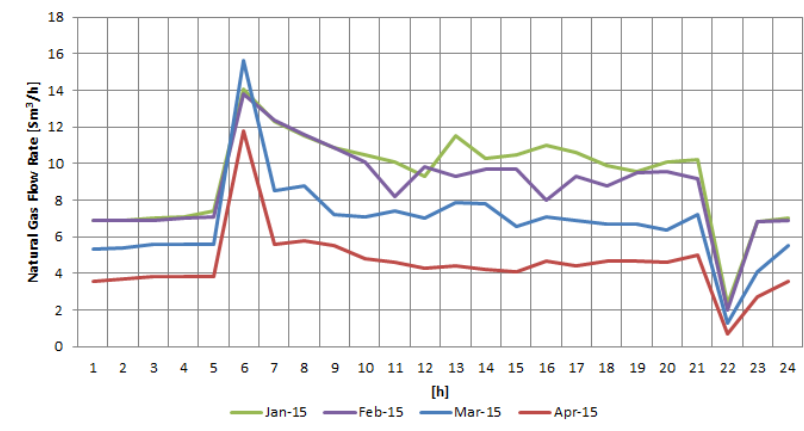

(a) during week days

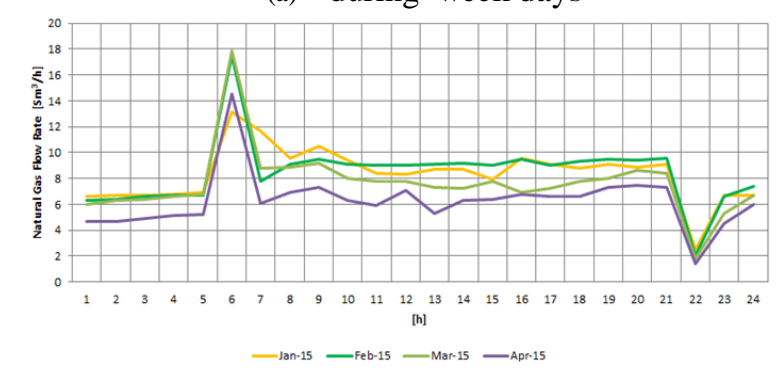

(b) during week-end days

Figure 17. Natural Gas consumption (Building 4)

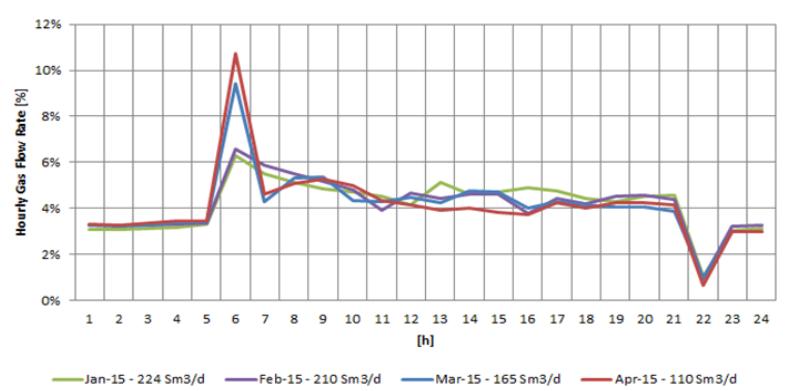

Figure 18. Hourly Percentage of Natural Gas consumption (Building 4)

\subsubsection{Building 5 - Tetti Primary School}

From the carpet plot, high internal temperatures (average around $23^{\circ} \mathrm{C}$ ) with peaks over $26^{\circ} \mathrm{C}$ can be detected (Fig.19). By correlating thermal consumption with HDD can be seen that to each $1^{\circ} \mathrm{C}$ variation correspond a variation in energy consumption of $6 \%$. Any hourly regulation is detected from gas consumption data.

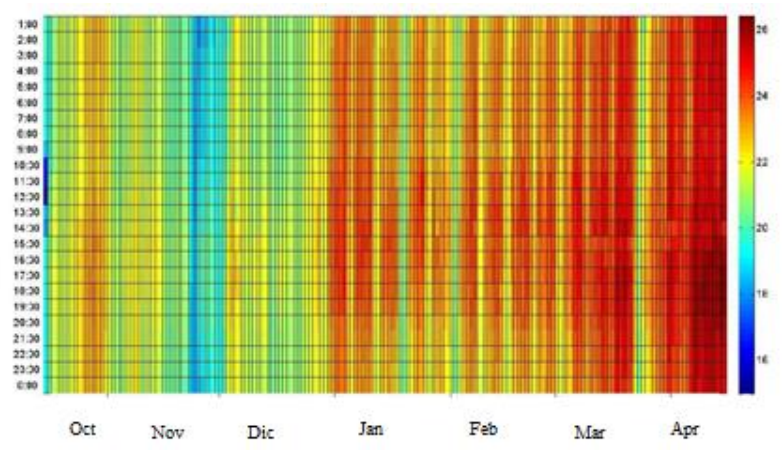

Figure 19. Internal temperature of Building 5

During week days (Fig. 20a), $73 \%$ of gas is consumed (46\% of gas is used from 5 am to 5 pm and $27 \%$ from $6 \mathrm{pm}$ 
to $4 \mathrm{am}$ ) while during Saturday and Sunday $27 \%$ of gas is used (Fig. 20b). As well as for building 4, by optimizing the regulation in the nights (no heating system) and the weekend (halve the working), $40 \%$ of gas consumption can be saved.

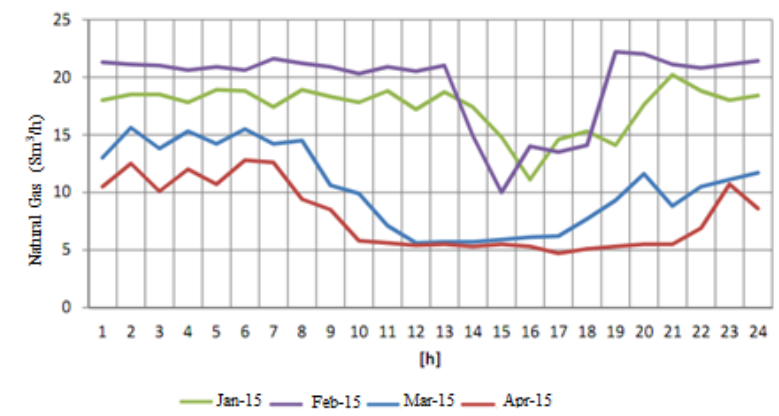

(a) during week days

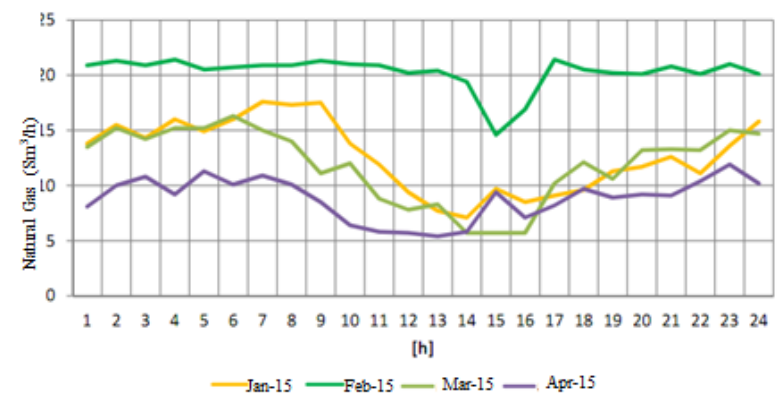

(b) during week - end days

Figure 20. Natural Gas Consumption

\subsection{Thermal dispersions}

From thermal imager's images it is possible to understand which are the principal components responsible of thermal loans. In Fig.21a, the presence of radiators sited under the windows in buildings 2 is visible. Moreover, dispersions from the balcony, the doors and windows are clearly identified.

The reinforced concrete structure of Building 3 can be seen in Fig. 21b. The thermal bridges between the soil and the basement as well as windows are responsible of main dispersions. The attic has a lower temperature with respect to the rest of the buildings and the façade masonry's loans are lower with respect to concrete structure.

In Building 4 (Fig. 21c), great dispersions from windows can be observed. Furthermore, in the upper left corner, the effects of solar warming are highlighted.

In Building 5 (Fig.21d), the effects of thermal bridges and windows dispersions are clearly visible.

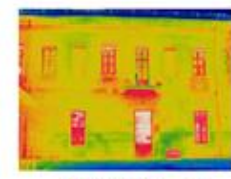

(a) Building 2

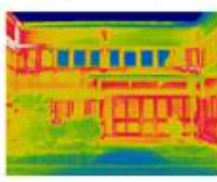

(c) Building 4

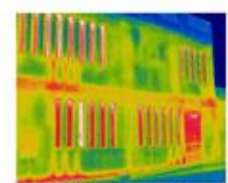

(b) Building 3

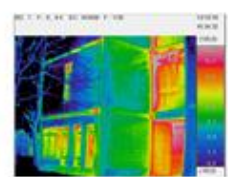

(d) Building 5
Figure 21. Thermographic camera's pictures

\section{PROPOSED MEASURES}

ENERGY

CONSERVATION

From previous analysis some general considerations can be introduced:

- most of the buildings has an oversized installed electric power and the possibility of changing the supply contract in a more advantageous one can be investigated

- most of the buildings has no hourly regulation of the thermal energy system and the heating system is not turned off during unoccupied time periods;

- most of the buildings has old single glaze windows.

For each building, specific energy conservation measures regarding thermal (Tab. 4) and electric consumptions are proposed.

Table 4. Energy conservation measures proposal (heating)

\begin{tabular}{|c|c|c|}
\hline \multicolumn{3}{|c|}{ Thermal related measures } \\
\hline Building & Criticality & Proposed measure \\
\hline $2,3,5$ & $\begin{array}{l}\text { Incorrect regulation } \\
\text { of the thermal heating } \\
\text { system }\end{array}$ & $\begin{array}{l}\text { Installation of thermal valves } \\
\text { and new regulation for } \\
\text { turning on/off the heating } \\
\text { system }\end{array}$ \\
\hline 3 & $\begin{array}{l}\text { Inefficient domestic } \\
\text { hot water (DHW) } \\
\text { production }\end{array}$ & $\begin{array}{l}\text { New regulation for the DHW } \\
\text { production and substitution } \\
\text { of circulation pumps }\end{array}$ \\
\hline 4 & $\begin{array}{l}\text { Absence of internal } \\
\text { temperature control }\end{array}$ & Installation of thermal valves \\
\hline 5 & $\begin{array}{l}\text { Inefficient heat } \\
\text { production }\end{array}$ & $\begin{array}{l}\text { Substitution of heating } \\
\text { boilers and circulation pumps }\end{array}$ \\
\hline 3,5 & $\begin{array}{l}\text { High dispersions from } \\
\text { windows }\end{array}$ & $\begin{array}{l}\text { Single-glaze windows } \\
\text { substitution }\end{array}$ \\
\hline
\end{tabular}

Considering the current natural gas price $\left(0.85 € / \mathrm{Sm}^{3}\right)$, by applying these mostly low cost measures, about $80,000 € / y$ can be saved.

Concerning electric consumption, all the buildings have similar conditions. Consequently, the same measures are proposed for all the structures: substitution of lamp bulbs with more efficient ones and, with the exception of Building 6 , investigating the feasibility of PV system installation (20 $\mathrm{kW})$.

\section{CONCLUSIONS}

In this paper a simple, flexible and economic procedure for metering energy consumption in public buildings is proposed. The analysis allows searching for major anomalies in building operation in order to propose energy conservation measures at low cost. This is helpful for planning energy retrofit measures, investigating the feasibility of new energy service contracts and identifying the opportunities of new regulation schedules of the energy system.

The selected public buildings represent a common situation of Italian existing buildings' energy use in which there is room for improvement associated with operators' behavior. The study has shown that Italian public buildings suffer from regulation problems regarding heating schedules and that this problem can be solved through simple monitoring campaign and change in regulation ensuring the same comfort levels. It can represents a good starting energy conservation solution toward more concrete structural 
renovation or component substitution involving large investment costs that can be not affordable at the moment for many public entities.

Concerning electric consumption, the study has demonstrated that there is a strong link between climate variables (external temperature and irradiation) and electricity usage, even if the constant value (k1) is predominant. Higher external temperatures implies higher heating needs and consequently a higher usage of heating systems auxiliaries and hot water appliances; while solar irradiation affects natural daylighting opportunities. Typically, the air temperature influences more the energy consumptions than solar irradiation.

The proposed case study demonstrates the efficacy of energy metering for optimizing the operation conditions of the building with measures at almost zero costs. Monitoring campaign for improving the building energy use can be easily implemented as schools or more general public buildings management policies' strategies. In particular, from the energy percentage of hourly load diagram (as represented in Fig.18) the thermal regulation can be easily understood and then improved.

The application of this procedure on a large stock may provide useful energy performance surveys for predicting with a good accuracy the thermal and electric loads during the year. This can be helpful for energy savings purposes, but can also represent a basis for deeper analyses related to renewables integration and control strategies proposals.

\section{ACKNOWLEDGEMENTS}

The authors are truly thankful to Prof. Cristiana Delprete of the Department of Mechanical and Aerospace Engineering (DIMEAS) of Politecnico di Torino and the Municipality of Rivalta di Torino (TO) for the precious support in the analysis.

\section{REFERENCES}

[1] European Parliament. Directive 2012/27/EU. Off. J. Eur. Union L315/1, 1-56 (2012).

[2] Hajdukiewicz, M., Byrne, D., Keane, M. M. and Goggins, J., "Real-time monitoring framework to investigate the environmental and structural performance of buildings," Build. Environ. vol. 86, no. 1-16, 2015. DOI: 10.1016/j.buildenv.2014.12.012.

[3] Fichera, A., Fortuna, L., Frasca, M., and Volpe, R., "Integration of complex networks for urban energy mapping," International journal of Heat and Technology, vol. 33, no. 4, 181-184, 2015. DOI: 10.18280/ijht.330423.

[4] Genco, A., Viggiano, A., Rospi, G., Cardinale, N. and Magi, V., "Dynamic modeling and simulation of buildings energy performance based on different climatic conditions," International journal of heat and technology, vol. 33, no. 4, pp. 107-116, 2015. DOI: 10.18280/ijht.330414.

[5] Melendez, J., Colomer, J., Massana, J. and Pous, C., "Case study multivariate," Energy Build., vol. 103, pp. 338-351, 2015. DOI: 10.1016/j.enbuild.2015.06.069 0378-7788.
[6] Hernandez, P., Burke, K. and Lewis, J. O., "Development of energy performance benchmarks and building energy ratings for non-domestic buildings: An example for Irish primary schools," Energy Build., vol. 40, pp. 249-254, 2008. DOI: 10.1016/j.enbuild.2007.02.020.

[7] Lourenço, P., Pinheiro, M. D. and Heitor, T., "From indicators to strategies: Key performance strategies for sustainable energy use in Portuguese school buildings," Energy Build., vol. 85, pp. 212-224, 2014. DOI: 10.1016/j.enbuild.2014.09.025.

[8] Menezes, A. C., Cripps, A., Bouchlaghem, D. and Buswell, R., "Predicted vs. actual energy performance of non-domestic buildings: Using post-occupancy evaluation data to reduce the performance gap," Appl. Energy, vol. 97, pp. 355-364, 2012. DOI: 10.1016/j.apenergy.2011.11.075.

[9] Hong, T., Koo, C. and Jeong, K., "A decision support model for reducing electric energy consumption in elementary school facilities," Appl. Energy, vol. 95, pp. 253-266, 2012

DOI:

10.1016/j.apenergy.2012.02.052.

[10] Santamouris, M., Mihalakakou, G., Patargias, P., Gaitani, N., Sfakianaki, K., Papaglastra, M., Pavlou, C., Doukas, P., Primikiri, E., Geros, V. Assimakopoulos, M. N., Mitoula, R. and Zerefos, S. "Using intelligent clustering techniques to classify the energy performance of school buildings," Energy Build., vol. 39, pp. 45-51, 2007. DOI: 10.1016/j.enbuild.2006.04.018.

[11] Corgnati, S. P., Corrado, V. and Filippi, M., "A method for heating consumption assessment in existing buildings: A field survey concerning 120 Italian schools," Energy Build., vol. 40, pp. 801-809, 2008. DOI: $10.1016 /$ j.enbuild.2007.05.011.

[12] Dall'O, G. and Sarto, L., "Potential and limits to improve energy efficiency in space heating in existing school buildings in northern Italy," Energy Build., vol. 67, pp. 298-308, 2013. DOI: 10.1016/j.enbuild.2013.08.001.

[13] Trejo-Perea, M. et al., "Development of a real time energy monitoring platform user-friendly for buildings," Procedia Technol., vol. 7, pp. 238-247, 2013. DOI: $10.1016 /$ j.protcy.2013.04.030.

[14] Yang, L., Yan, H. and Lam, J. C., "Thermal comfort and building energy consumption implications - A review," Appl. Energy, vol. 115, pp. 164-173, 2014. DOI: 10.1016/j.apenergy.2013.10.062.

[15] Batista, A. P., Freitas, M. E. and Jota, F. G., "Evaluation and improvement of the energy performance of a building's equipment and subsystems through continuous monitoring," Energy Build., vol. 75, pp. 368-381, 2014. DOI: 10.1016/j.enbuild.2014.02.029.

[16] Miller, C., Nagy, Z. and Schlueter, A., "Automated daily pattern filtering of measured building performance data," Autom. Constr., vol. 49, pp. 1-17, 2015. DOI: 10.1016/j.autcon.2014.09.004.

[17] De Wilde, P., et al., "Building simulation approaches for the training of automated data analysis tools in building energy management," Adv. Eng. Informatics, 27, pp. 457-465, 2013. DOI: 10.1016/j.aei.2013.05.001. 
[18] Lajevardi, B., Haapala, K. R. and Junker, J. F., "Realtime monitoring and evaluation of energy efficiency and thermal management of data centers," J. Manuf. Syst. vol. 37, pp. 511-516, 2014. DOI: 10.1016/j.jmsy.2014.06.008.

[19] Pesola, A., Serkkola, A., Lahdelma, R. and Salminen, P., "Multicriteria evaluation of alternatives for remote monitoring systems of municipal buildings," Energy
Build. vol. 72, pp. 229-237, 2014. DOI: 10.1016/j.enbuild.2013.10.037.

[20] Mutani G., Pastorelli M., and De Bosio F., "A model for the evaluation of thermal and electric energy consumptions in residential buildings: The case study in Torino (Italy)," ICRERA-2015, IEEE Conference Publications, pp. 1399-1404. DOI: 10.1109/ICRERA.2015.7418637. 